Jean-François Hardy MD FRCPC, Jean Charest MD FRCPC, Gilles Girouard MD FRCPC, Yves Lepage PHD

\title{
Nausea and vomiting after strabismus surgery in preschool children
}

The incidence of nausea and vomiting after strabismus surgery was studied in 64 children aged one to six years. Incidence was determined in the post-anaesthesia recov. ery room (PARR), in the same day surgery (SDS) unit, and at home on days one and two after the operation. After induction of anaesthesia, the children received an intravenous injection of droperidol ( $50 \mu \mathrm{g} \cdot \mathrm{kg}^{-1}$ ) or saline in a double-blind randomized fashion, and an intrave. nous injection of glycopyrrolate $\left(7.5 \mu \mathrm{g} \cdot \mathrm{kg}^{-1}\right)$ or atropine $\left(10 \mu \mathrm{g}^{-1} \mathrm{~g}^{-1}\right)$ in an open randomized fashion. The incidence of emetic symptoms was highest in the SDS unit and at home on day one. Droperidol slightly but significantly delayed awakening and was not, at least in this particular age group, associated with any difference in postoperative sickness. Despite theoretical advantages, glycopyrrolate offered no significant benefit over atropine as far as postoperative emesis was concerned.

\section{Key words}

ANAESTHESIA: paediatric, ophthalmologic, outpatient; vOMITING: incidence; ANAESTHETICS INTRAVENOUS: droperidol; PREMEDICATION: glycopyrrolate.

From the Departments of Anaesthesia, Mathematics and Statistics, University of Montreal, MaisonneuveRosemont and Sainte-Justine Hospitals, Montreal, Canada.

Address correspondence to: Dr J.F. Hardy, Dept. of Anaesthesia, Maisonneuve-Rosemont Hospital, 5415 l'Assomption Boulevard, Montreal, Quebec, Canada, H1T 2M4.

Presented at the 1985 Annual Meeting of the Canadian Anaesthetist's Society in Toronto, Ontario.
The frequency of postoperative nausea and vomiting is reported to be high in children ${ }^{1}$ particularly after opthalmic surgery. ${ }^{2}$ Postoperative vomiting may be severe enough to cause dehydration, or prevent the child from being sent home on the day surgery is performed on an outpatient basis. Ultra low dose droperidol $\left(5 \mu \mathrm{g} \cdot \mathrm{kg}^{-1}\right)$ appears to be an effective antiemetic when administered in adults during anaesthesia. ${ }^{3,4}$ However, in children under the age of 11 , this dose does not significantly reduce vomiting. ${ }^{5}$ The incidence of postoperative vomiting has been shown to decrease with age ${ }^{1,5}$ and conversely, the effectiveness of droperidol as a prophylactic antiemetic seems to increase with age. ${ }^{5}$ Doses of approximately $50 \mu \mathrm{g} \cdot \mathrm{kg}^{-1}$ have been shown to reduce the incidence of nausea and vomiting after ophthalmic surgery in adults ${ }^{2}$ and possibly in a paediatric population where ages ranged from 2.1 to 17.8 years. $^{6}$

We therefore undertook this study with three objectives. The first was to determine the incidence of nausea and vomiting after strabismus surgery in a more homogeneous group of children. Younger children (ages one to six years) are the most likely to present for this type of surgery. ${ }^{7}$ Since the evolution of emetic symptoms at home is not known, we extended the study to the first two postoperative days. Secondly, we wished to prospectively study the influence of a moderate dose of droperidol $\left(50 \mu \mathrm{g} \cdot \mathrm{kg}^{-1}\right)$ on the incidence of postoperative emetic symptoms in this particular age group. Finally, since emetic symptoms are thought to be in part caused by the oculo-cardiac reflex (OCR), ${ }^{2}$ we postulated that glycopyrrolate, more effective than atropine in preventing the $\mathrm{OCR},{ }^{8}$ might be associated with a lower incidence of postoperative nausea and vomiting. 


\section{Methods}

A double-blind prospective study was undertaken in 80 ASA physical status I or II children aged one to six years undergoing strabismus surgery on an outpatient basis. The study was approved by the Ethics Committee of Montreal's Ste-Justine Hospital, and informed consent was obtained for all children. When meeting with the adult responsible for the child, the objectives of the study were explained and a simple questionnaire relating to emetic symptoms on postoperative days one and two was handed out for future completion. Parents were instructed to report the presence or absence of nausea (including retching) or vomiting. Retching was defined as an active effort by the child, with no expulsion of stomach contents. These definitions were used since they are standard in our operating room area.

The children were randomly assigned to a control or a treatment group and a glycopyrrolate or atropine group. Placebo or droperidol was administered in a double-blind fashion. We thought it was necessary that the anaesthetists be informed which anticholinergic drug was administered. The anaesthetics were given by all members of the Department of Anaesthesia. A "step by step" printed protocol accompanied each child who took part in the study.

The children were not premedicated. General anaesthesia was induced with a mixture of 66 per cent nitrous oxide in oxygen and halothane (maximum two per cent inspired concentration) by face mask and a Jackson-Rees system. Patients were given d-tubocurarine $\left(50 \mu \mathrm{g} \cdot \mathrm{kg}^{-1}\right)$ and atropine $\left(10 \mu \mathrm{g} \cdot \mathrm{kg}^{-1}\right)$ or glycopyrrolate $\left(7.5 \mu \mathrm{g} \cdot \mathrm{kg}^{-1}\right)$ and the coded medication intravenously. After receiving succinylcholine $\left(1.5 \mathrm{mg} \cdot \mathrm{kg}^{-1}\right)$, the patient's trachea was intubated. Spontaneous breathing was allowed to resume and anaesthesia was maintained with halothane two per cent in a mixture of nitrous oxide and oxygen $\left(\mathrm{FrO}_{2} .33\right)$. Upon completion of surgery, the child was given oxygen ( 100 per cent) for three minutes and the pharynx was suctioned. While still under deep general anaesthesia, the child was extubated and transferred to the postanaesthesia recovery room (PARR). Oral airways were not necessary in the postoperative period. After satisfying criteria for discharge from the PARR, the child was transferred to the same day surgery (SDS) unit. Criteria for discharge included a maximal postanes- thesia recovery score (based on adequacy of respira. tion, skin color, movement and consciousness) and the absence of any surgical complication (e.g., excessive eye pain or bleeding). If necessary, dimenhydrinate $1 \mathrm{mg} \cdot \mathrm{kg}^{-1} \mathrm{IM}$ was administered to control nausea and vomiting in the PARR or in the SDS unit. No analgesics were administered at any stage during or after the anaesthetic. When fully alert and able to tolerate oral fluids, the child was discharged from hospital.

Results were entered on a special data collection sheet which followed the child through surgery, the recovery room and the SDS unit. The collection sheet was then returned to the Department of Anaesthesia. Awakening time (from extubation to maximal recovery score), time to discharge from hospital (from extubation), presence or absence of nausea, retching or vomiting were noted by the same PARR and SDS nurses, who were not told which medication had been given the children. Nurses did not ask about nausea, but waited for it to be volunteered when possible, considering the age group involved. Parents completed the questionnaire relating to postoperative emetic symptoms and usually returned it within the week.

Statistical evaluation of the data was performed by the Department of Mathematics and Statistics of the University of Montreal. Two-way analysis of variance, Fisher's exact test and Chi-square were used where appropriate and $p<0.05$ was considered significant. All results are expressed as mean \pm standard deviation.

\section{Results}

Of the 80 children studied, 16 had to be excluded from the study because their data collection sheets had been improperly filled out. Our results are therefore based on the remaining 32 children in both the control and droperidol group. Patient characteristics are shown in Table I. Fifteen patients in the control group and 18 patients in the droperidol group received atropine, while 17 patients in the control group and 14 in the droperidol group received glycopyrrolate.

Table II shows duration of anaesthesia and surgery, and time for awakening and discharge from hospital. Despite a significantly shorter anaesthetic and surgical procedure, patients in the droperidol group had a significantly prolonged awakening 
TABLE I Patient characteristics and number of extra-ocular muscles operated per child

\begin{tabular}{lllll}
\hline & Sex & Age (years) & Weight $(\mathrm{kg})$ & Number of muscles operated \\
\hline $\begin{array}{l}\text { Control group } \\
(\mathrm{n}=32)\end{array}$ & $\left.\begin{array}{l}17 \% \\
159\end{array}\right)$ & $3.25 \pm 1.54$ & $15.72 \pm 4.82$ & $1.7 \pm 0.5$ \\
$\begin{array}{l}\text { Droperidol group } \\
(\mathrm{n}=32)\end{array}$ & $\left.\begin{array}{l}19 \sigma^{\circ} \\
139\end{array}\right\}$ & $3.25 \pm 1.56$ & $16.07 \pm 5.07$ & $1.6 \pm 0.65$ \\
\hline
\end{tabular}

Mean $\pm \mathrm{SD}$

No significant statistical difference was observed between groups.

TABLE II Duration of anaesthesia and surgery, and time for awakening and discharge (minutes)

\begin{tabular}{lllll}
\hline & Anaesthesia & Surgery & Awakening & Dischargefrom Hospital \\
\hline Control & $53 \pm 16$ & $31 \pm 12$ & $27 \pm 13$ & $195 \pm 66$ \\
Droperidol & $45 \pm 12$ & $24 \pm 11$ & $34 \pm 10$ & $201 \pm 71$ \\
p & .044 & .027 & .036 & .676 \\
\hline
\end{tabular}

p was determined by two way analysis of variance, controlling for the use of different anticholinergic drugs.

time. However, time to discharge was similar in both groups.

The incidence of postoperative nausea and vomiting in hospital and at home is shown in Tables III and IV. The use of droperidol was not associated with any statistically significant difference in the incidence of postoperative nausea and vomiting in the PARR, the SDS unit, or at home on either the first or second postoperative day.

Statistical analysis showed that postoperative emetic symptoms were not significantly related to sex.

No significant difference in the incidence of emetic symptoms was observed with glycopyrrolate in lieu of atropine, in the control or in the droperidol group.

Three patients in the control group and one patient in the droperidol group needed intramuscular dimenhydrinate to control emesis while in hospital. At home, four patients in the control group and one patient in the droperidol group needed oral dimenhydrinate to control emesis. These differences were not significant.

Since the incidence of nausea and vomiting was similar in both groups (Tables III and IV), we thought it interesting to study the evolution of these symptoms over time in the whole patient population. There was a significant association $(p=$
0.0105 ) between nausea and vomiting in the PARR and in the SDS unit. Despite this association, a clinically significant number of patients ( 27 per cent of the whole patient population), not yet symptomatic in the PARR, presented nausea and vomiting in

TABLE III Incidence of postoperative emetic symptoms in hospital

\begin{tabular}{llll}
\hline & PARR & SDS & Hospital (total) \\
\hline Control & $23 \%$ & $37 \%$ & $41 \%$ \\
& $(\mathrm{n}=7)$ & $(\mathrm{n}=11)$ & $(\mathrm{n}=13)$ \\
Droperidol & $6 \%$ & $42 \%$ & $41 \%$ \\
& $(\mathrm{n}=2)$ & $(\mathrm{n}=13)$ & $(\mathrm{n}=13)$ \\
\hline
\end{tabular}

No significant statistical difference was observed between groups.

TABLE TV Incidence of postoperative emetic symptoms at home

\begin{tabular}{llll}
\hline & Day I & Day 2 & Home (total) \\
\hline Control & $56 \%$ & $7 \%$ & $56 \%$ \\
& $(\mathrm{n}=18)$ & $(\mathrm{n}=2)$ & $(\mathrm{n}=18)$ \\
Droperidol & $46 \%$ & $13 \%$ & $50 \%$ \\
& $(\mathrm{n}=15)$ & $(\mathrm{n}=4)$ & $(\mathrm{n}=16)$ \\
\hline
\end{tabular}

No significant statistical difference was observed between groups. 
the SDS unit. When emetic symptoms were present in hospital, they very likely persisted at home, since a highly significant relationship existed between the two $(p=0.0007)$. Furthermore, emetic symptoms were maximal at home on the first postoperative day (Table IV).

\section{Discussion}

We studied the incidence of postoperative emetic symptoms in the age group most likely to present for strabismus surgery, and the evolution of this complication on the first two days after discharge from hospital.

We found a mean incidence of nausea and vomiting of 41 per cent during the hospital stay and 53 per cent at home. The incidence of postoperative emesis, with or without droperidol, was not dramatically different from the 43 per cent incidence found by Abramowitz et al. when droperidol $\left(75 \mu \mathrm{g} \cdot \mathrm{kg}^{-1}\right)$ was given IV, ${ }^{9}$ nor from the $30-35$ per cent incidence reported by other authors for different surgical procedures in similar groups. 1,5 The large difference in the incidence of postoperative emesis in Abramowitz's control group ( 85 per cent) and our patients (41 per cent) is difficult to explain. Theoretically, since their patients were older (two to 13 years), the incidence of this complication should have been lower in their control group than in ours. ${ }^{1,5}$ Possible explanations for this higher incidence are threefold. First, we did not aspirate gastric contents at the beginning and at the end of anaesthesia thus avoiding repeated or prolonged pharyngeal stimulation. Second, the depth of anaesthesia may have been different. A lighter level of anaesthesia has been associated with a decreased incidence of emetic symptoms. ${ }^{1}$ Considering that we used a concentration of two per cent halothane, this explanation is difficult to accept unless one is ready to postulate that deeper levels of anaesthesia may blunt the OCR and thus contribute to the decreased incidence of postoperative nausea and vomiting. Third, when considering that the type of stimulus is the determinant factor of the OCR, ${ }^{10}$ gentler manipulation of the extra-ocular muscles by ophthalmologists sensitive to the problem may be associated with a decreased incidence of postoperative emesis. However, the correlation between the eliciting of the OCR and the occurrence of postoperative sickness remains to be demonstrated.

No indication of severity can be assessed from this study. The assessment of nausea and vomiting is a complex problem which has recently been extensively reviewed by Morrow. ${ }^{12}$ Nausea is a subjective experience and is best assessed by the person experiencing the symptom. Clearly, its approach is difficult in this patient population. Vomiting, on the other hand, can reliably be assessed by an observer. Ideally, the averaging of two independent observations will yield the most reliable ratings of vomiting. This assessment is time-consuming and was not feasible in this experiment. According to the same author, retching also needs to be differentiated from vomiting. Since such a detailed account was impossible, we chose to report emetic symptoms (including nausea, retching and vomiting) as a simple present/absent assessment. The use of dimenhydrinate in the postoperative period was an attempt to provide an "indirect measure of nausea and vomiting."12 This indirect index of severity did not reveal a significant difference between groups. However, one must remember that the groups were relatively small, the use of dimenhydrinate was rare, and this approach remains indirect evidence. Therefore, firm conclusions regarding the severity of symptoms are difficult to hold. From this study, any beneficial effect of droperidol on severity of symptoms appears to be, at best, minimal. The same limitations to assessment of nausea and vomiting by PARR and SDS unit nurses apply to questionnaires completed by parents and may further be compounded by greater inter-observer variability. Despite these (important) limitations, we feel that this study adequately reflects the incidence of observable emetic symptoms in this particular age group. Thus, the effect of droperidol on the incidence of postoperative emetic symptoms in these children was statistically insignificant and clinically perceived as such.

Emetic symptoms were maximal in the SDS unit and on the first postoperative day. Knowledge of this time frame and of the strong association between hospital and home sickness may help provide the best care for these patients.

Motion sickness is common in children. It was not assessed in this study, as we felt that excluding those children would be clinically unrealistic. We did not attempt to relate duration of journey home to timing of emetic episodes. Even so, motion sickness does not appear to have played a significant 
role in the genesis of emetic symptoms, considering that (1) the association between nausea and yomiting in hospital and at home is so highly significant $(p=0.0007)$ that the journey is unlikely to have modified the evolution of symptoms; (2) all children had to live within a 60-minute distance from hospital to be admitted as out-patients.

Droperidol $\left(50 \mu \mathrm{g} \cdot \mathrm{kg}^{-1}\right)$ given intravenously at the beginning of anaesthesia slightly delayed awakening and was not, at least in this particular age group, an effective prophylactic antiemetic. The dose of $50 \mu \mathrm{g} \cdot \mathrm{kg}^{-1}$ was chosen as it is likely to be effective $e^{2,6}$ and associated with minimal side effects. Increased drowsiness ${ }^{6,9}$ and extrapyramidal symptoms ${ }^{11}$ have been reported with higher doses in children. Droperidol induced somnolence did not interfere with hospital release in this study nor in others using similar or even higher doses. ${ }^{2,6,9}$ However, this side effect was not outweighed by any beneficial effect.

Although the present study was not designed to relate the OCR with postoperative nausea and vomiting, we thought that glycopyrrolate in relatively high doses might be useful in preventing emetic symptoms, for the following reasons: (1) its effectiveness in preventing the $O C R,{ }^{8}$ and (2) the possible reduction in gastric acid secretion. The present study, however, shows that glycopyrrolate did not affect emetic symptoms.

In conclusion, the incidence of emetic symptoms after strabismus surgery in children aged one to six years is approximately 50 per cent, is maximal on the first postoperative day and is neither modified by the use of $50 \mu \mathrm{g} \cdot \mathrm{kg}^{-1}$ of droperidol given during anaesthesia, nor by the choice of the anticholinergic drug.

\section{Acknowledgements}

The authors gratefully acknowledge the enthusiastic assistance of the members of the Department of Anaesthesia, the PARR and SDS unit nurses of Sainte-Justine Hospital who also helped collect the data. We also wish to thank Mrs. Rose Warnock of the Research Center of Maisonneuve-Rosemont Hospital for her invaluable help in reviewing the manuscript and Ms. Louise Chartier and Ilona Schmidt for their secretarial assistance.

\section{References}

1 Purkis IE. Factors that influence post-operative vomiting. Can Anaesth Soc J 1964; 11: 335-53.

2 Iwamoto K, Schwartz $H$. Antiemetic effect of droperidol after ophthalmic surgery. Arch Ophthalmol 1978; 96: 1378-9.

3 Shelley ES. Antiemetic effect of ultra low dose droperidal. Am Society of Anesthesiologists 1978; Scientific Abstracts, p. 633.

4 Wetchler BV, Collins IS, Jacob L. Antiemetic effects of droperidol on the ambulatory surgery patient. Anesthesiology Rev 1982; 9: 23-6.

5 Rita $L$, Goodarzi $M$, Seleny $F$. Effect of low dose droperidol on post-operative vomiting in children. Can Anaesth Soc J 1981; 28: 259-62.

6 Abramowitz MD, Elder PT, Friendly DS, Broughton WL, Epstein BS. Antiemetic effectiveness of intraoperatively administered droperidol in pediatric strabismus outpatient surgery. Preliminary report of a controlled study. J Pediat Ophthalmol Strabismus 1981; 18 : 22-7.

7 FranceNK. Anesthesia for pediatric ophthalmologic surgery, In: Pediatric Anesthesia, 1 st Edition. Edited by GA Gregory, New York, Churchill-Livingstone, 1983.

8 Mirakhur RK, Jones CJ, Dundee JW, Archer DB. I.M. or I.V. atropine or glycopyrrolate for the prevention of oculocardiac reflex in children undergoing squint surgery. Br J Anaesth 1982; 54: 1059-63.

9 Abramowitz MD, Tae HO, Epstein BS, Ruttimann $V E$, Friendly $D S$. The antiemetic effect of droperidol following outpatient strabismus surgery in children. Anesthesiology 1983; 59: 579-83.

10 Blanc VF, Hardy JF, Milot J, Jacob JL. The oculocardiac reflex: a graphic and statistical analysis in infants and children. Can Anaesth Soc J 1983; 30: 360-9.

11 Dupré $L$, Stieglitz $P$. Extrapyramidal syndromes after premedication with droperidol in children. Br J Anaesth 1980; 52: 831-3.

12 Morrow GR. The assessment of nausea and vomiting: past problems, current issues, and suggestions for future research. Cancer 1984; 53: 2267-78. 


\section{Résumé}

Nous avons étudié la fréquence des nausées et vomissements après chirurgie du strabisme chez un groupe d'enfants âgés de un à six ans. L'incidence de cette complication a été relevée à la salle de réveil, à l'hospitalisation d'un jour, et à la maison pendant les deux premiers jours après l'opération. Après induction de l'anesthésie au masque, les enfants recevaient une injection intraveineuse de droperidol $\left(50 \mu \mathrm{g} \cdot \mathrm{kg}^{-1}\right)$ ou de salin, à double insu, selon une distribution aléatoire, et une injection intraveineuse de glycopyrrolate 7.5 $\left.\mu \mathrm{g} \cdot \mathrm{kg}^{-1}\right)$ ou d'atropine $\left(10 \mu \mathrm{g} \cdot \mathrm{kg}^{-1}\right) d^{\prime}$ 'une façon randomisée, mais connue de l'investigateur. L'incidence des nausées et vomissements a été maximale àl'hospitalisation d'un jour et à la maison pendant le premier jour post-opératoire. Le droperidol a retardé le réveil de façon modeste, mais statistiquement significative et n'a en rien modifié l'évolution des nausées et vomissements post-opératoires. De même, le glycopyrrolate, malgré certains avantages théoriques, $n^{\prime}$ a pas diminué l'incidence de cette complication post-opératoire, comparativement à l'atropine. 